A C G

Org. Commun. 10:2 (2017) 122-129

organic

communications

publications

\title{
Preparation and biological evaluation of novel acylhydrazide derivatives of 2,3-dichloronaphthoquinone
}

\author{
Jomana Elaridi ${ }^{* 1}$, Nour Bou Karroum ${ }^{1,2}$, Kamal Bouhadir ${ }^{2}$, \\ Maamoun Fatfat ${ }^{3}$ and Hala Gali-Muhtasib ${ }^{3}$
}

\author{
${ }^{I}$ Department of Natural Sciences, School of Arts and Sciences, Lebanese American University, Beirut, \\ 1102-2801, Lebanon \\ ${ }^{2}$ Department of Chemistry, Faculty of Arts and Sciences, American University of Beirut, Beirut, 11 - \\ 0236, Lebanon \\ ${ }^{3}$ Department of Biology, and Department of Anatomy, Cell Biology and Physiological Sciences, \\ American University of Beirut, Beirut, 11-0236, Lebanon
}

(Received March 09, 2017; Revised May 05, 2017; Accepted May 08, 2017)

\begin{abstract}
Naphthoquinones have been reported to possess a variety of pharmacological properties including antibacterial, antifungal, antiviral, anti-inflammatory, anti-artherosclerotic and anticancer effects. We have successfully synthesized a series of novel naphthoquinone acylhydrazides. The straightforward synthesis of these molecules involves a coupling reaction between 2,3-dichloro-1,4-naphthoquinone and several alkyl and aromatic hydrazides and the hydrazides of the pyrimidine nucleobases, uracil and thymine. The product hydrazides were isolated in good yields and completely characterized by spectroscopic analysis. Biological evaluation against human colon cancer HCT116 cells and human breast cancer MCF-7 cells indicated that the novel hydrazides possessed significant anticancer activity.
\end{abstract}

Keywords: 2,3-dichloro-1,4-naphthoquinone; acylhydrazide; 1,4-napththoquinone-2-acyl hydrazides; pyrimidine nucleobase. (c) 2017 ACG Publications. All rights reserved.

\section{Introduction}

Naphthoquinones are compounds found in higher plants which have been used in folk medicine for the treatment of various diseases. ${ }^{1}$ Naphthoquinones have been reported to possess a variety of pharmacological properties including antibacterial, antifungal, antiviral, anti-inflammatory, antiartherosclerotic and anticancer effects. ${ }^{2}$ 1,4-Naphthoquinone $\mathbf{1}$ encompasses the quinone pharmacophore which is typically associated with most of the biological activity of similar molecules. ${ }^{3}$ Our interest in naphthoquinones was stimulated by the literature which is abundant with research involving the isolation and subsequent biological testing of naphthoquinones from natural products and novel synthetic naphthoquinone derivatives. ${ }^{1}$ The quinonoid anticancer drugs such as mitomycin $\mathrm{C}$, daunorubicin, doxorubicin and mitoxantrone have been used in the treatment of various

\footnotetext{
* Corresponding author: E-Mail: jomana.aridi@lau.edu.lb
} 
types of cancers, including solid tumors. ${ }^{4}$ Mitomycin C 2, a bioreductive alkylating agent, expresses antitumor activity by the reductive redox-cycling hydroquinone. ${ }^{5}$ Another representative quinone derivative with antitumor activity, Doxorubicin 3, (Figure 1) acts as an intercalator. ${ }^{6}$ The mechanism of cytotoxic action is related to the interference of naphthoquinones in the DNA synthesis. ${ }^{7}$<smiles>O=C1C=CC(=O)c2ccccc21</smiles>

1<smiles>CO[C@@]12[C@H](COC(N)=O)C3=C(C(=O)C(C)=C(N)C3=O)[C@@H]3CN1[C@@H]2N3</smiles>

2<smiles>COc1cccc2c1C(=O)c1c(O)c3c(c(O)c1C2=O)C[C@@](O)(C(=O)CO)C[C@@H]3O[C@H]1C[C@H](N)[C@H](O)[C@H](C)O1</smiles>

3

Figure 1. Some medicinally important naphthoquinone derivatives

\section{Background}

Recent studies have shown that the incorporation of a chlorine atom into 1,4-naphthoquinone derivatives is essential for antifungal activity. ${ }^{8}$ In addition, 1,4-naphthoquinones possessing an amino or a substituted amino group in the 2-position, have been used in a variety of medical and biological applications, including as antituberculars, antimalarials, antibacterials, antitumor agents, larvicides and molluscicides, herbicides, and fungicides. ${ }^{9-13}$ The presence of the nitrogen atom allows modulation of the substituent's effects on the electronic properties of the quinone system, as well as modification of the geometry of the neutral molecules and of their reduction intermediates. ${ }^{14}$

Hydrazides are also an important class of compounds utilized in pharmaceutical products. ${ }^{15}$ Hydrazides have been associated with antibacterial, antifungal, antihelminthic and anticonvulsant activities. ${ }^{16-19}$ In addition to their biological properties, hydrazides are starting materials for a range of potentially bioactive derivatives, such as hydrazones, oxadiazoles, triazoles and pyrazolones.

Many pyrimidine nucleosides such as gemcitabine, cytarabine, 5-fluorodeoxyuridine, capecitabine, and decitabine, are clinically used for the treatment of both solid and hematological cancers. ${ }^{20,21}$ Despite recent advances in the development of anticancer drugs, the design and preparation of novel nucleoside-based anticancer therapeutics for the treatment of drug-resistant tumors remains an important research goal worldwide.

For this reason we were interested in investigating the preparation of hydrazide derivatives of 2,3-dichloro-1,4-naphthoquinone which incorporate these important pharmacophores. Many pyrimidine nucleosides such as gemcitabine, cytarabine, 5-fluorodeoxyuridine, capecitabine, and decitabine, are clinically used for the treatment of both solid and hematological cancers. ${ }^{20,21}$ Despite recent advances in the development of anticancer drugs, the design and preparation of novel nucleoside-based anticancer therapeutics for the treatment of drug-resistant tumors remains an important research goal worldwide. For this reason we were interested in investigating the preparation of hydrazide derivatives of 2,3-dichloro-1,4-naphthoquinone which incorporate these important pharmacophores.

\section{Experimental}

A solution of alkyl hydrazide (1.0 - $5.0 \mathrm{mmol}$ ) and 2,3-dichloro-1,4-naphthoquinone (1 equiv, 1.0 - $5.0 \mathrm{mmol})$ in DMSO (20 ml) was stirred for $24-72 \mathrm{~h}$ at room temperature. The reaction mixture was then diluted with water $(20 \mathrm{~mL})$ and stirred for $10-15 \mathrm{~min}$. The formed precipitate was filtered, washed with water and purified by trituration from dioxane and hexane and dried under reduced pressure to give the pure product as a solid. All the products were identified on the basis of their spectral data. The ${ }^{1} \mathrm{H},{ }^{13} \mathrm{C}$ NMR and HRMS spectra, and LCMS traces of all the synthesized compounds are provided in the Supporting Information.

HCT116 p53+/+ human colon cancer cells and MCF-7 (p53+/+, noninvasive) human breast cancer cell lines were cultured in RPMI 1640 (Sigma-Aldrich, UK) with 20mM HEPES and L- 
Glutamine at $37^{\circ} \mathrm{C}$ in a humidified atmosphere of $5 \% \mathrm{CO}_{2}$ and $95 \%$ air. Media was supplemented with $1 \%$ Penicillin-Streptomycin $(100 \mathrm{U} / \mathrm{ml})$ and 10\% heat-inactivated FBS (Sigma-Aldrich, Germany), $1 \%$ non essential amino acids and $1 \%$ of Na pyruvate.

The cells were seeded at $12 \times 10^{3}$ cells/well in 96-well plates and treated with different concentrations of compounds $\mathbf{6 a}-\mathbf{j}$ for $24 \mathrm{~h}$. Control cells were treated with $\mathbf{6 a}-\mathbf{j}$ such that the concentration of DMSO was less than $0.3 \%$. The inhibition of cell viability (expressed as percentage of control) was measured by the Cell Titer 96 non-radioactive cell proliferation kit (Promega Corp, Madison, Wisconsin, USA). This assay is an MTT based method that measures the ability of metabolically active cells to convert tetrazolium salt into a blue formazan product, and its absorbance is recorded at $595 \mathrm{~nm}$. Each value is the mean $\pm \mathrm{SD}$ of two separate experiments each done in triplicates. The $\mathrm{IC}_{50}$ represents the concentration at which $50 \%$ of the cells are viable.

\section{Present Study}

\subsection{Chemistry}

The reaction of 2,3-dichloro-1,4-naphthoquinone 4 with nucleophilic hydrazides 5a-j proceeds by a nucleophilic substitution reaction. The preparation of the desired acylhydrazide derivatives of 2,3-dichloro-1,4-naphthoquinone 6a-j was achieved by amination of 2,3-dichloro-1,4naphthoquinone $\mathbf{4}$ with a variety of alkyl, aromatic and pyrimidine-based hydrazides. The starting aliphatic hydrazides were prepared from the corresponding esters $\mathbf{7 a - j}$ by reaction with hydrazine hydrate in methanol in the presence of a catalytic amount of trifluoroacetic acid according to an established literature procedure (Scheme 1). ${ }^{22}$

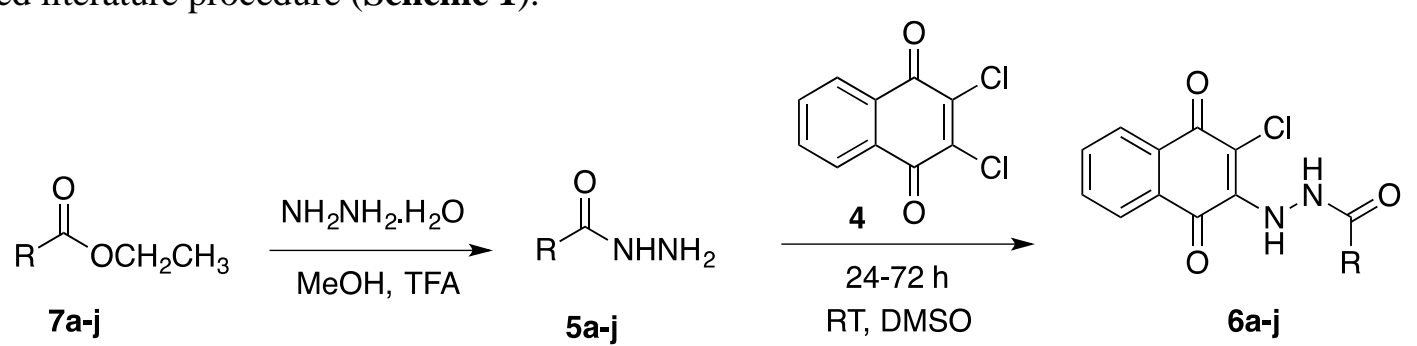

Scheme 1. Synthesis of compounds $\mathbf{6 a - j}$

Reaction of the resultant hydrazides 5a-j with 2,3-dichloro-1,4-naphthoquinone in DMSO at room temperature from $24-72$ hours led to substitution of one of the chloro-substituents with the nucleophilic hydrazide. A related reaction in the literature involving 2,3-dichloro-1,4-naphthoquinone and an ibuprofen hydrazide derivative was performed in refluxing ethanol and the product was recrystallized from the said solvent. ${ }^{23}$ Interestingly, in our case, attempts to react 2,3-dichloro-1,4naphthoquinone with the various acylhydrazides at reflux in several solvents, including ethanol, lead to decomposition products that could not be characterized. We found it was essential to perform the coupling reaction at room temperature in the dissolving solvent DMSO. In fact, the product hydrazides 6a-j decomposed on silica and were heat sensitive which made purification by column chromatography and recrystallization impractical. Ultimately, the naphthoquinone hydrazide derivatives 6a-j were obtained as solids in good yields after trituration from a mixture of dioxane and hexane (Table 1). The structures of the synthesized compounds have been confirmed by NMR, IR and mass spectral analysis which are provided in the supplementary information. 
Table 1. Synthesis of 1,4-naphthoquinone acylhydrazide derivatives

\begin{tabular}{|c|c|c|c|c|c|}
\hline Product & Hydrazide $\left(\mathrm{RCONHNH}_{2}\right)$ & $\begin{array}{l}\text { Reaction } \\
\text { Time }\end{array}$ & Yield & m.p. $\left({ }^{\circ} \mathrm{C}\right)$ & $\begin{array}{c}\text { Molecular } \\
\text { Formula }\end{array}$ \\
\hline $6 \mathbf{a}$ & & $24 \mathrm{~h}$ & $63 \%$ & $144-147$ & $\mathrm{C}_{15} \mathrm{H}_{15} \mathrm{ClN}_{2} \mathrm{O}_{3}$ \\
\hline $6 \mathbf{b}$ & & $24 \mathrm{~h}$ & $76 \%$ & $137-140$ & $\mathrm{C}_{17} \mathrm{H}_{21} \mathrm{ClN}_{2} \mathrm{O}_{3}$ \\
\hline $6 c$ & & $24 \mathrm{~h}$ & $73 \%$ & $94-97$ & $\mathrm{C}_{21} \mathrm{H}_{25} \mathrm{ClN}_{2} \mathrm{O}_{3}$ \\
\hline 6d & & $12 \mathrm{~h}$ & $81 \%$ & $140-143$ & $\mathrm{C}_{22} \mathrm{H}_{29} \mathrm{ClN}_{2} \mathrm{O}_{3}$ \\
\hline $6 e$ & & $72 \mathrm{~h}$ & $75 \%$ & 104-107 & $\mathrm{C}_{24} \mathrm{H}_{33} \mathrm{ClN}_{2} \mathrm{O}_{3}$ \\
\hline $6 f$ & & $24 \mathrm{~h}$ & $61 \%$ & $140-143$ & $\mathrm{C}_{28} \mathrm{H}_{41} \mathrm{ClN}_{2} \mathrm{O}_{3}$ \\
\hline $6 \mathrm{~g}$ & & $24 \mathrm{~h}$ & $52 \%$ & $>260$ & $\mathrm{C}_{17} \mathrm{H}_{11} \mathrm{ClN}_{2} \mathrm{O}_{3}$ \\
\hline $6 \mathbf{h}$ & & $24 \mathrm{~h}$ & $67 \%$ & $253-255$ & $\mathrm{C}_{16} \mathrm{H}_{11} \mathrm{ClN}_{4} \mathrm{O}_{5}$ \\
\hline $6 \mathbf{i}$ & & $24 \mathrm{~h}$ & $68 \%$ & $253-256$ & $\mathrm{C}_{17} \mathrm{H}_{13} \mathrm{ClN}_{4} \mathrm{O}_{5}$ \\
\hline $6 j$ & $\mathrm{NHNH}_{2}$ & $24 \mathrm{~h}$ & $65 \%$ & $213-216$ & $\mathrm{C}_{18} \mathrm{H}_{15} \mathrm{ClN}_{4} \mathrm{O}_{5}$ \\
\hline
\end{tabular}

An important feature of the NMR spectra of the acylhydrazides $\mathbf{6 a - j}$ is the presence of duplicate sets of some proton and carbon resonances, attributed to the existence of $E$ - and $Z$-isomers in DMSO-d6 solution (Figure 2).

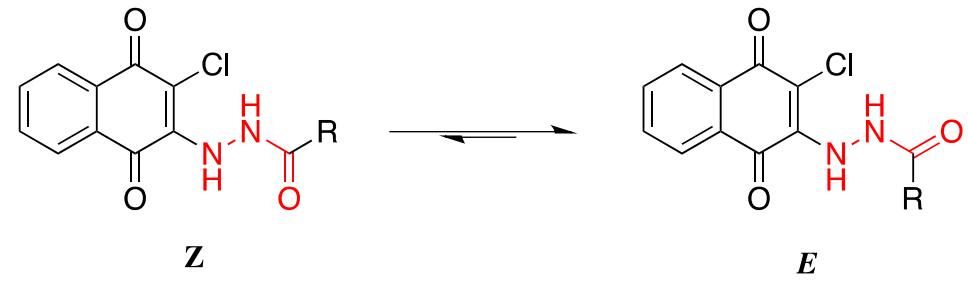

Figure 2. $E / Z$-isomers of the acylhydrazide 1,4-naphthoquinone products 
Determination of $E$ - or Z- geometry by NMR spectroscopy was based on earlier reports in the literature that acylhydrazides are generally more stable in their $E$-isomeric forms ${ }^{24-27}$ Knapp originally suggested that the $Z / E$-equilibrium of hydrazides is not only governed by steric factors but also by the electronic effects. ${ }^{24}$ Specifically, the preference for $E$-isomers in acylhydrazides can be attributed to destabilization of the Z-isomer due to lone pair-lone pair repulsion between electrons on the carbonyl oxygen and the hydrazide nitrogen (Figure 3). Knapp's model was supported by research conducted by Perdicchia and Licandro who studied the Z/E-equilibrium observed in a new series of trisubstituted hydrazides. $^{27}$

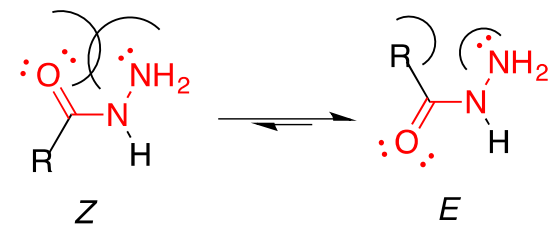

Figure 3. E/Z-equilibrium of acylhydrazides

In our case, the percentage of major, presumably $E$-, was relatively consistent at $70 \%$ whereas the minor Z-isomer accounted for 30\% of the product distribution (Table 2). Poor solubility of the stearic hydrazide conjugate made characterization difficult, and consequently separate isomeric peaks could not be identified. In addition, attempts to perform an NMR temperature study to evaluate the characteristics of the $E$-/Z-equilibrium and determine the coalescence temperature proved futile due to the heat sensitive nature of the compounds.

Table 2. E/Z-Isomer distribution of 1,4-naphthoquinone acylhydrazide derivatives 6

\begin{tabular}{ccc}
\hline Product & $\% E$ & $\% Z$ \\
\hline $\mathbf{6 a}$ & $71 \%$ & $29 \%$ \\
$\mathbf{6 b}$ & $71 \%$ & $29 \%$ \\
$\mathbf{6 c}$ & $73 \%$ & $27 \%$ \\
$\mathbf{6 d}$ & $72 \%$ & $28 \%$ \\
$\mathbf{6 e}$ & $69 \%$ & $31 \%$ \\
$\mathbf{6}$ & - & - \\
$\mathbf{6 g}$ & $73 \%$ & $27 \%$ \\
$\mathbf{6 h}$ & $62 \%$ & $38 \%$ \\
$\mathbf{6}$ & $57 \%$ & $43 \%$ \\
$\mathbf{6 j}$ & $77 \%$ & $23 \%$ \\
\hline
\end{tabular}

\section{Biological Assay}

The literature is inundated with reports describing the anticancer effects of naphthoquinones and their derivatives. ${ }^{1-5}$ Thus, the naphthoquinone acylhydrazides $\mathbf{6 a - j}$ were evaluated for their cytotoxic activity against MCF-7 and HCT116 cell lines using MTT viability assay. As a positive control, the biological activity of Doxorubicin was evaluated in parallel at three different concentrations $(0.75,10,50 \mu \mathrm{M})$ by the MTT viability assay (Figure 3$)$. Interestingly, all compounds showed dose-dependent inhibitory effect on the cancerous cell lines and were most active at $50 \mu \mathrm{M}$ concentrations. Several compounds, such as $\mathbf{6 b}, \mathbf{6 e}$ and $\mathbf{6 h}$ were active at concentration as low as 10 $\mu \mathrm{M}$. However, the most effective compound $\mathbf{6 c}$, with the undecylenic sidechain, had an $\mathrm{IC}_{50}$ value of $33 \mu \mathrm{M}$ on MCF-7 cells (Table 3). The significantly enhanced activity of this derivative may be attributed to the unsaturated fatty acid-like sidechain which has previously been reported to increase cytotoxic activity. ${ }^{28}$ The reported activity of 2,3-dichloro-1,4-naphthoquinone $\mathbf{4}$ is comparable to the synthesized derivatives with $\mathrm{IC}_{50} 31 \mu \mathrm{M}$ against MCF-7 tumor cell lines. ${ }^{29}$ The activity of each compound varied between the two cell lines, indicating cell type specificity and suggesting different interactions with the cells. 

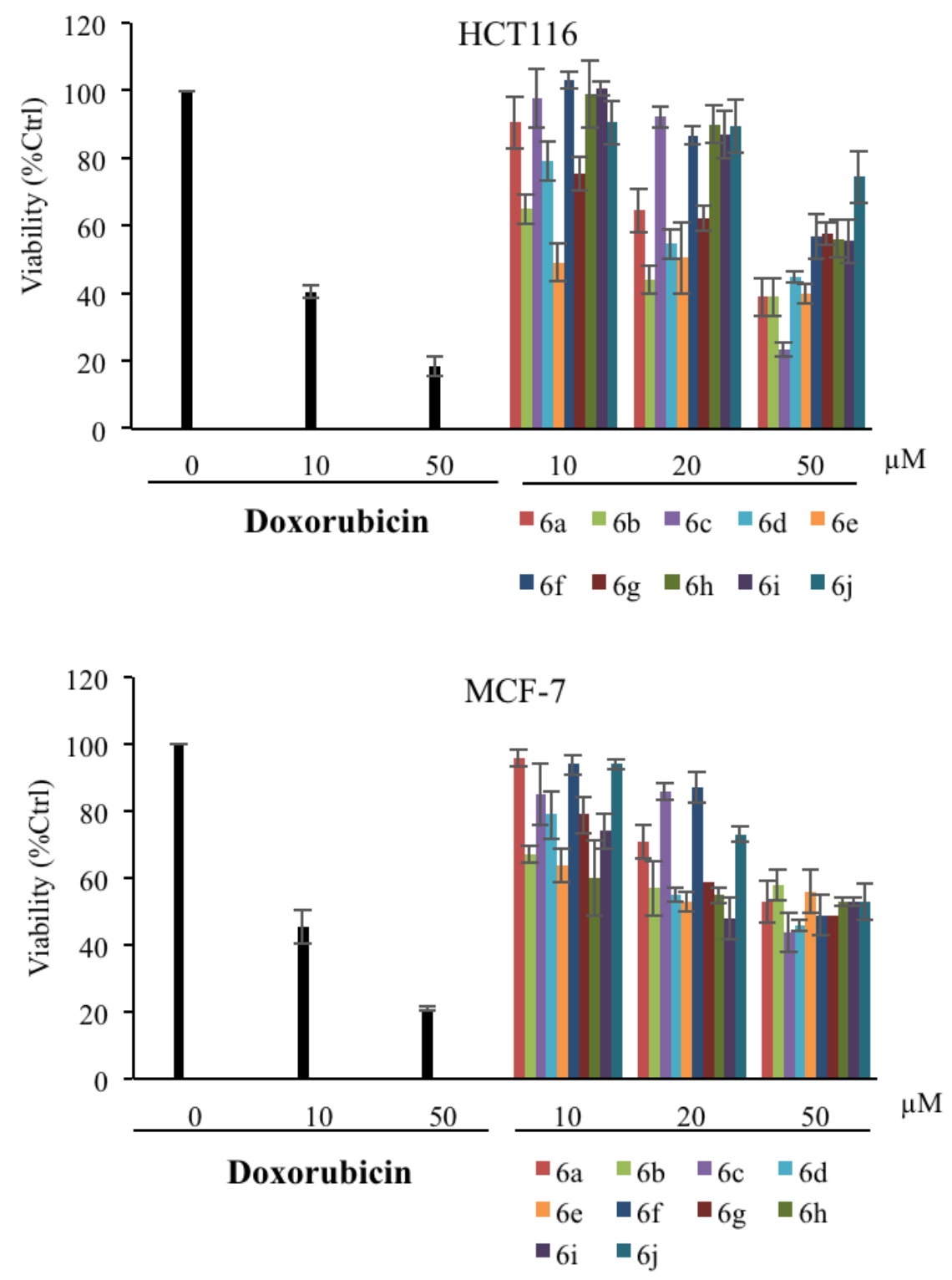

Figure 3. Cell viability of HCT116 and MCF-7 cells upon treatment with 6a-j as determined by MTT assay. Cell viability of the positive control Doxorubicin is also presented.

Table 3. $\mathrm{IC}_{50}$ Values $(\mu \mathrm{M})$ of acylhydrazides $\mathbf{6 a - j}$

\begin{tabular}{ccc}
\hline Compounds & HCT116 & MCF-7 \\
\hline $\mathbf{6 a}$ & $41 \pm 2.4$ & $52 \pm 1.1$ \\
$\mathbf{6 b}$ & $41 \pm 3.2$ & $60 \pm 2.4$ \\
$\mathbf{6 c}$ & $33 \pm 1.9$ & $54 \pm 1.7$ \\
$\mathbf{6 d}$ & $45 \pm 2.5$ & $46 \pm 2.8$ \\
$\mathbf{6 e}$ & $41 \pm 1.9$ & $57 \pm 3.5$ \\
$\mathbf{6 f}$ & $58 \pm 1.5$ & $49 \pm 1.2$ \\
$\mathbf{6 g}$ & $58 \pm 2.9$ & $50 \pm 2.7$ \\
$\mathbf{6 h}$ & $57 \pm 3.4$ & $53 \pm 1.5$ \\
$\mathbf{6 i}$ & $56 \pm 2.5$ & $53 \pm 1.7$ \\
$\mathbf{6 j}$ & $100 \pm 5.4$ & $52 \pm 1.8$ \\
\hline
\end{tabular}




\section{Conclusion}

The facile and straightforward synthesis of a series of novel 1,4-naphthoquinone acylhydrazide derivatives is presented. The product hydrazides were prepared in good to excellent yields by the reaction of various aliphatic and aromatic hydrazides with 2,3-dichloro-1,4naphthoquinone at room temperature. The structures of obtained compounds were characterized using the spectroscopic methods $\left({ }^{1} \mathrm{H}\right.$ and ${ }^{13} \mathrm{C}$ NMR, IR, HRMS, LC-MS). Biological evaluation indicates that several of the naphthoquinone acylhydrazide derivatives possess significant anticancer activity, as the percentage of viable cells decreased significantly after treatment of both colon and breast cancer cells with these molecules. Although the derivatized naphthoquinone hydrazides showed lower activity than the chemotherapy drug Doxorubicin, their ability to target two types of solid tumors (breast and colon) is promising; thus future studies should explore their possible molecular mechanism of action.

\section{Acknowledgements}

The authors gratefully acknowledge the financial support of the Lebanese National Council for Scientific Research (LNCSR).

\section{Supporting Information}

Supporting Information accompanies this paper on http://www.acgpubs.org/OC

\section{References}

[1] Pinto, A. V.; de Castro, S. L. The trypanocidal activity of naphthoquinones: A review. Molecules 2009, 14, 4570-4590.

[2] Bhasin, D.; Chettiar, S.; Etter, J.; Mok, M.; Li, P. Anticancer activity and SAR studies of substituted 1,4naphthoquinones. Bioorg. Med.Chem. 2013, 21, 4662-4669.

[3] Ashe, C. Antitumor quinones. Mini Rev. Med. Chem. 2005, 5, 449-467.

[4] Brandy, Y.; Brandy, N.; Akinboye, E.; Lewis, M.; Mouamba, C.; Mack, S.; Butcher, R. J.; Anderson, A. J.; Bakare, O. Synthesis and characterization of novel unsymmetrical and symmetrical 3-halo- or 3-methoxysubstituted 2-dibenzoylamino-1,4-naphthoquinone derivatives. Molecules 2013, 18, 1973-1984.

[5] Alcaín, F. J.; Villalba, J. M. NQO1-directed antitumor quinones. Expert Opin. Ther. Patents 2007, 17, 649-665.

[6] Rhee, H.; Kwon, Y.; Chung, H.; Lee, S.; Choo, H. P. Synthesis, cytotoxicity and topoisomerase II inhibitory activity of benzonaphthofurandiones. Bull. Korean Chem. Soc. 2011, 32, 2391-2396.

[7] Baker, R. A.; Tatum, J. H.; Nemec, S., Jr. Antimicrobial activity of naphthoquinones from Fusaria. Mycopathologia 1990, 111, 9-15.

[8] Tandon, V. K.; Maurya, H. K.; Mishra, N. N.; Shukla, P. K. Design, synthesis ad biological evaluation of novel nitrogen and sulfur containing hetero-1,4-naphthoquinones as potent antifungal and antibacterial agents. Eur. J. Med. Chem. 2009, 44, 3130-3137

[9] Silver, R. F.; Holmes, H. L. Synthesis of some 1,4-naphthoquinones and reactions relating to their use in the study of bacterial growth inhibition. Can. J. Chem. 1968, 46, 1859-1864.

[10] Oeriu, I. Relation between the chemical structure and antitubercular activity of various alpha-napththoquinone derivatives. Biokhimiia 1963, 28, 380-383.

[11] Prescott, B. Potent antimalarial agents. Derivatives of 2-chloro-1,4-naphthoquinone. J. Med. Chem. 1969, 12, $181-182$

[12] Hodnett, E. M.; Wongwiechintana, C.; Dunn, W. J. $3^{\text {rd }}$; Marrs, P. Substituted 1,4-naphthoquinones vs. the ascitic sarcoma 180 of mice. J. Med. Chem. 1983, 26, 570-574.

[13] Clark, N. G. The fungicidal activity of substituted 1,4-naphthoquinones. Part III: Amino, anilino and acylamino derivatives. Pestic. Sci. 1984, 15, 235-240.

[14] Benites, J; Valderrama, J. A.; Bettega, K.; Pedrosa, R. C.; Calderon, P. B.; Verrax, J. Biological evaluation of donor-acceptor aminonaphthoquinones as antitumor agents. Eur. J. Med. Chem. 2010, 45, 6052-6057.

[15] Toliwal, S.; Jadav, K.; Patel, K. Synthesis and biological evaluation of fatty hydrazides of by-products of oil processing industry. Indian J. Pharm. Sci. 2009, 71, 144-148.

[16] Mir, I.; Siddiqui, M. T.; Comrie, A. Antituberculosis agents. I. Alpha-(5-(2-furyl)-1,2,4-triazol-3-ylthio) acethydrazide and related compounds. Tetrahedron 1970, 26, 5235-5237. 
[17] Degener, E.; Scheinplug, H.; Schemelzer, H. G. Brit Patent Number: 1035,474, 1967.

[18] Cavier, R.; Rips, R. Dihydrazides, a new class of anthelmintics. J. Med. Chem. 1965, 8. 706-708.

[19] Trepanier, D. L.; Wagner, E. R.; Harris, G.; Rudzik, A. D. 1,4,5,6-Tetrahydro-as-triazines. I. Sulfuric acid catalyzed condensation of nitriles and hydrazino alcohols. J. Med. Chem. 1966, 9, 881-885.

[20] Bourderioux,A.; Naus, P.; Perlíkova, P.; Pohl, R.; Pichova, I.; Votruba, I.; Dzubak, P.; Konecny, P.; Hajduch, M.; Stray, K. M.; Wang, T.; Ray, A. S.; Feng, J. Y.; Birkus, G.; Cihlar, T.; Hocek, M. Synthesis and significant cytostatic activity of 7-hetaryl-7-deazaadenosines. J. Med. Chem. 2011, 54, 5498-5507.

[21] Galmarini, C. M.; Mackey, J. R.; Dumontet, C. Nucleoside analogues and nucleobases in cancer treatment. Lancet Oncol. 2002 3, 415-424.

[22] Karabanovich, G.; Zemanova, J.; Smutny, T.; Szekely, R.; Sarkan, M.; Centarova, I.; Vocat, A.; Pavkova, I.; Conka, P.; Nemecek, J.; Stolarikova, J.; Vejsova, M.; Vavrova, K.; Klimesova, V.; Hrabalek, A.; Pavek, P.; Cole, S.; Mikusova, K.; Roh, J. J. Med. Chem. 2016, 59, 2362-2380.

[23] Mohamed, S. K.; Albayati, M. R. ; Younes, S. H. H.; Abed-Alkareem, M. G. Functionalization of ibuprofen core structure compound: synthesis of new potential chemotherapeutic agents incorporating ibuprofen substructure. Chem. Sci. J. 2013, CSJ-97.

[24] Knapp, S.; Toby, H.; Sebastian, M.; Krogh-Jesperson, K.; Potenza, J. A. Relative reactivity and structures of benzoyltrimethylhydrazine and 1-benzoyl-2-methylpyrazolidine. J. Org. Chem. 1981, 46, 2490-2497.

[25] Ghelfi, F.; Parsons, A. F. $N, N$-(Dimethylamino)-2-pyrrolidinones from the Rearrangement of $N$-Allyl- $N^{\star}, N^{\star}-$ dimethyl-2,2-dichlorohydr- azides promoted by $\mathrm{CuCl}-N, N, N^{\star}, N^{\star}$--tetramethylethylendiamine. J. Org. Chem. 2000, 65, 6249-6253.

[26] Le Grel, P.; Salaun, A.; Mocquet, C.; Le Grel, B.; Roisnel, T.; Potel, M. Z/E Isomerism in $\mathrm{N}^{\alpha}$ - $\mathrm{N}^{\alpha}$-disubstituted hydrazides and the amidoxy bond: Application to the conformational analysis of pseudopeptides built of hydrazinoacids and $\alpha$-aminoxyacids. J. Org. Chem. 2011, 76, 8756-8767.

[27] Licandro, E.; Perdicchia, D. N-Acylhydrazines: Future perspectives offered by new syntheses and chemistry. Eur. J. Org. Chem. 2004, 665-675.

[28] Breyer, S.; Effenberger, K.; Schobert, R. Effects of thymoquinone-fatty acid conjugates on cancer cells. ChemMedChem 2009, 4, 761-768.

[29] Tapia, R. A.; Cantuarias, L.; Cuéllar, M.; Villena, J. Microwave-assisted reaction of 2,3-dichloronaphthoquinone with aminopyridines. J. Braz. Chem. Soc. 2009, 20, 999-1002.

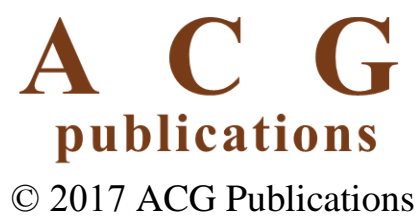

